\title{
Decision Support System for Detecting, Diagnosing and Suggesting Remedial Measures for Building Cracks
}

\author{
M.A. Jayaram \\ Director \\ Department of MCA \\ Siddaganga Institute of \\ Technology, Tumkur, India
}

\author{
Amrutha P.B. \\ Project Student \\ Department of MCA \\ Siddaganga Institute of \\ Technology, Tumkur,India
}

\author{
Chaithanya D.P. \\ Project Student \\ Department of MCA \\ Siddaganga Institute of \\ Technology, Tumkur, India
}

\begin{abstract}
Decision support system plays very crucial role in aiding decision making when huge abstract data is available. This paper elaborates on a decision support system which can detect, diagnose and suggest remedial measures on building cracks. The system caters to cracks that would appear in ceilings, walls, floors and beams in a building. The knowledge base for the system was collected from building codes, Journals and also by discussions with construction experts. The user is provided with an excellent interface with visual and audio visual guidance. Further, the user needs to answer the queries posed by the system in Yes/No format. Forward chaining is adapted to arrive at detection and to offer suggestions on remedial measures. This system is of immense help to builders, practicing civil engineers and students. The evaluation of the system is carried out in presence of expert and the system has shown satisfactory performance.
\end{abstract}

\section{Keywords}

Decision support, building cracks, knowledge base, forward chaining, inference, remedial measures.

\section{INTRODUCTION}

Decision Support System is increasingly becoming a crucial function for decision makers in various organizations. Wellknown facts about decision support system are

- To help decision makers to gather and to interpret information.

- To build foundation for decision making in a specified domain.

- To facilitate seamless functioning of a system even with the absence of a concerned human expert.

Decision support systems (DSS) are computer based information systems designed in such a way that help managers to select one of the many alternative solutions to a problem. It is possible to automate decision making process in a large computer based decision support system which could analyze huge amount of information. In essence, decision support system helps to reduce cost, increase portability, enhance quality, and will help to manage situations. This paper presents a decision support system developed to diagnose building cracks and to suggest remedial measures there upon. The rest of the paper is organized as follows, section II elaborates related works, a brief presentation about the types of cracks that are seen in a building are briefly presented in section III. Section IV describes the development of decision support system, a session with the system is illustrated in section $\mathrm{V}$, and finally the paper concludes in section VI.

\section{RELATED WORK}

There have been decision support systems developed by the experts in various scientific, engineering and other allied fields. A decision support system that could be used in tourism management organization has been developed [1]. In this application, tourism destination management is treated as a system comprising of a complex mixture of social and economical entities. In an application related to decision support system in e-commerce [2], e-commerce related activities are integrated. It also covers some critical issues related to e-commerce such as, semi structured and unstructured situations, business needs, cost, and complexity. The decision support system so developed suggests future strategies. Intelligent system for diagnosing learning disorders in children has been reported [3]. This system provides powerful means for obtaining solutions to four types of disorders namely, Dyslexia, Dysgraphia, Dyspraxia and Dyscalculia. The system facilitates easy interaction with the users. The development of computerized decision support system for nursing homes has been presented [4]. This research work is about the thinking strategies and clinical reasoning processes of registered nurses and to implement a support system integrating electronic health care record for preventing ulcers and malnutrition among people. A Decision Support System for Wool Classification has been attempted [5]. The system provides advice in the decision making during grading and classification process of wool. This expert system incorporates decision making component of the human expert. A medical decision support system that could facilitate physicians to make clinical decisions and to improve quality of medical care has been reported [6]. This system is also capable of making decisions based on the diagnosis of estimated health situation in a comprehensive set of recommendations for the ethical development and application. Noor et al [7], have evaluated the association between attributes for house breaking crimes identified from police reports while developing a related decision support system. They have done various statistical tests to ensure the significant attributes to be utilized in the development of a decision support system. Navaneeth Valia et al [8] have developed a DSS for Tuberculosis diagonosability using fuzzy logic concepts. This system also adapts emblematic approach using fuzzy inference system and being enabled to forecast the existence of bacterium and provides support platform to pulmonary researchers in identifying the ailment effectively. Ermatita et al [9] have developed a system that could be used to identify what genes that was active in the human body using microarray data. This is a significant development as detection of gene mutation is an activity that can provide contribution in the medical field. Detection of mutated gene is needed to avoid the diseases caused by them such as cancer. ELECTRE method, which is a Multi-Attribute 
Decision Making, which is a method in modeling multicriteria GDSS, has been used to develop the system. Decision support system for real estate Industry has been elaborated [10]. This system would be useful for risk managers interested in real estate investment. The system deals with main risk management related decisions that real estate professionals made on a daily basis. Risk management decision models are selected from an extensive literature review. These models are incorporated into a decision support system. A set of reports that will support risk management real estate decisions are designed and implemented in a prototype built to demonstrate the potential of this technology in the real estate industry. The database of the decision support is populated with a sample of data collected from the real estate market of the state of California USA and results were generated to illustrate how reports can be used to support real estate risk management decisions. Tripathy [11] has reported a decision support system that is capable of monitoring the employees in respect of their attendance, activities, responsibilities, time keeping and approvals. The system is claimed to be an effective tool in generating reports containing decisions that are to be taken by the management in improving the functionality of employees.

\section{BUILDING CRACKS}

Building cracks are very significant problem in every concrete and masonry building. There are multiple reasons for the development of the building cracks. Before deciding on restoration or repair methods it is pertinent to identify the causes. It can only be controlled using suitable materials and appropriate construction techniques [12]. The cracks found in buildings can be grouped under two types the non - structural cracks and the structural cracks. Structural cracks appear due to the induced stresses in the building materials. They may also appear due to incorrect design, faulty construction, overloading, shrinkage of soil and excessive deformation. Non - structural cracks are due to thermal changes, bad workmanship, improper material and faulty work. The details of cracks that appear in various components of building is presented.

\subsection{Cracks In Ceiling}

Cracks in in ceilings will always create a sense of insecurity in the occupants. The propagation, the structure and the width of the cracks that appear on ceiling depends on many factors. Some of them could be improper curing, poor foundation. Some of the locations or reasons for appearance of ceiling cracks may be summarized [13].

- Large ceiling areas which span greater than 15 feet.

- In the areas adjacent and parallel to framing members with in the same ceiling area.

- Areas subjected to high temperature and humidity variations.

- Interior areas that are left unconditioned over long periods of time.

- Improper placement of floor and ceiling joists.

However different conditions apply for the onset of cracks in ceiling. Some of the configurations of ceiling cracks that are most commonly noticed are spider web cracks, vertical cracks, bowed ceiling cracks, straight cracks and cracks with innumerable branches [14]. Some of the broad remedial measure includes installing spatial blocks, fixing plywood straps, stitching and the like.

\subsection{Cracks in Walls}

It is a non - structural crack. Wall cracks are most commonly appearing crack on building. Wall cracks occur usually due to poor construction practice and are common both in new and old buildings [15]. Some of the causes for the cracks on walls could be [16]

- Slab (roof) deflection

- Differential strain from stress and temperature changes

- Roof expansion and construction

- Creep and shrinkage cracking

- Poor details and improper construction

- Foundations and settlements

All materials that make up a building are in a constant state of movement, for accommodating such movements and controlling cracks there are two techniques available. They are to provide reinforcement and to provide control joints. Some of the other causes could be the weather condition, electrical inferences and thermal contraction and expansion. Wall cracks are categorized into three types, they are horizontal, vertical and stair step cracks. Horizontal cracks are due to heavy, wet, soil. Vertical cracks are the effect of minor settling in a poured concrete wall. Stair step cracks are observed only in foundation block, they look like steps and these types of cracks are also noticed on bowed basement walls. One of the best ways to seal wall cracks is by adopting the flexi repair span repair cracks system [15], epoxy injection and the like.

\subsection{Cracks in Columns}

Columns are usually struck with structural cracks.. Column cracks are divided into horizontal, diagonal and corrosion/bond cracks [17]. These cracks are caused due to [18]

\section{- Eccentricity of concrete columns}

- Corrosion of reinforcement in concrete columns

- Increased load on concrete columns

Stitching, gravity filling, dry packing and polymer impregnation [15] are the methods can be adopted to refit the column cracks.

\subsection{Cracks in Beams}

Beam cracks are structural cracks. The main causes of cracks in beams are due to [19]

- $\quad$ increased shear stress

- corrosion or insufficient concrete cover

- $\quad$ increased bending stress in beams

- compression failure in beams

Usually they occur at the maximum moment region. These cracks characteristics are maximum width at tension face of the beam converge towards top/bottom and occur in singly or in group. Types of beam cracks are flexural cracks, shear flexural cracks, tension cracks, torsional cracks, bond slip cracks and disturbance cracks. Some of the techniques to cure cracks on the beam are epoxy injection, routing and sealing, drilling and plugging etc... [15]. 


\subsection{Cracks in Floors}

The reasons for cracks formation are associated with low concrete strength due to the lack of water for cement hydration, absence of shrinkage seams in floor structure, wrong reinforcement and excess thickness of strengthening mineral coating of concrete floor which initiates crack formation [20] and also from water table level variation, subsidence of soil. These cracks may be continuous and hairline crack. Several types of floor cracks are shrinkage cracks, settlement cracks, cracks due to improper jointing and continuous external restraint and basement cracks [21]. Following two methods are adopted to repair this cracks they are Sulfo-aluminate grouts and Lignosulphate based injection grouts.

\section{DEVELOPMENT OF THE SYSTEM}

The decision support system for detecting and suggesting remedial measures for building cracks. The data and the pertinent information, the code provisions and remedial measures were garnered by referrals and having discussions with the construction engineers. To build and also to program the interface engine knowledge net as shown in fig. 1 is developed and used. The system is coded in visual C\# and is highly user friendly; so that even a novice will be able to participate in detection of cracks. The system is developed in a modular format. The modules are interfaced through .txt files. The various components of the system are elaborated in the following paragraphs.

\subsection{Interface Engine}

The interface engine performs forward chaining to arrive at expeditious inferences depending on the context. Sample segments of inference engine are given below.

\section{Example 1:}

IF: the crack is present at the middle of the ceiling

AND: if the building is multistoried one

AND: if any wet related problem on the ceiling

AND: curing is not done properly at the construction stage

AND: if the building settlement has seen

THEN: the crack is structural and is spider web crack.

\section{Example 2:}

IF: the building is exposed to heat

AND: if the building foundation condition is poor

AND: if the building is multistored one

AND: if the crack is observed near the electric line

THEN: the cracking can be the result of one or a Combination of factors such as drying shrinkage, thermal contraction or expansion.

Example 3:

IF: the crack is present along the junction of two Different surfaces

AND: is excessive movement of surface fungus on floors

AND: if water leakage present on the floor

AND: foundation settlement problem

THEN: it is a shrinkage crack. It is formed due to the Uniformity of a wall has been interrupted inside Corners.

\subsection{User Interface}

The user interface is very user friendly. Novice can handle this tool without any difficulties. It suggests the remedial measures in the form of tips to users for the particular problem on building cracks.

\section{A SESSION WITH THE SYSTEM}

The system starts with the query session. The questions posed to the user on the screen. First user has to select the component in which cracks are noticed like ceiling, wall, beam, column and floor. Then Depending upon the observation user would choose either yes or no button using radio buttons. To get the clear view of the cracks from the users, some pictures also shown. Video clippings were also shown. User can further continue by answering in yes/no mode. Figures 2-6 shows typical query sessions for the five locations of the cracks considered. Figure 4 shows the remedial measure report for the particular crack that has been identified by the system. 


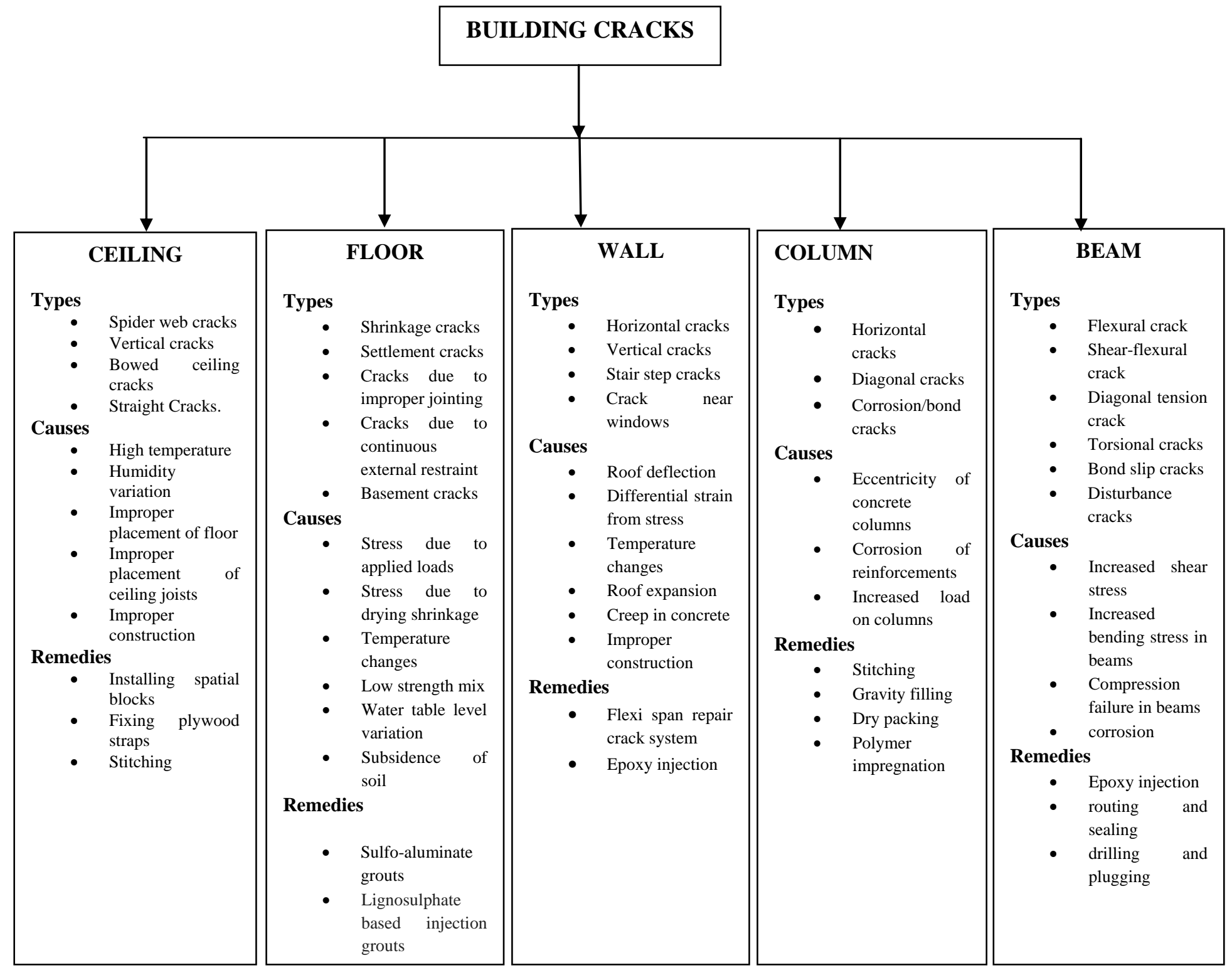

Figure 1: The Knowledge Net

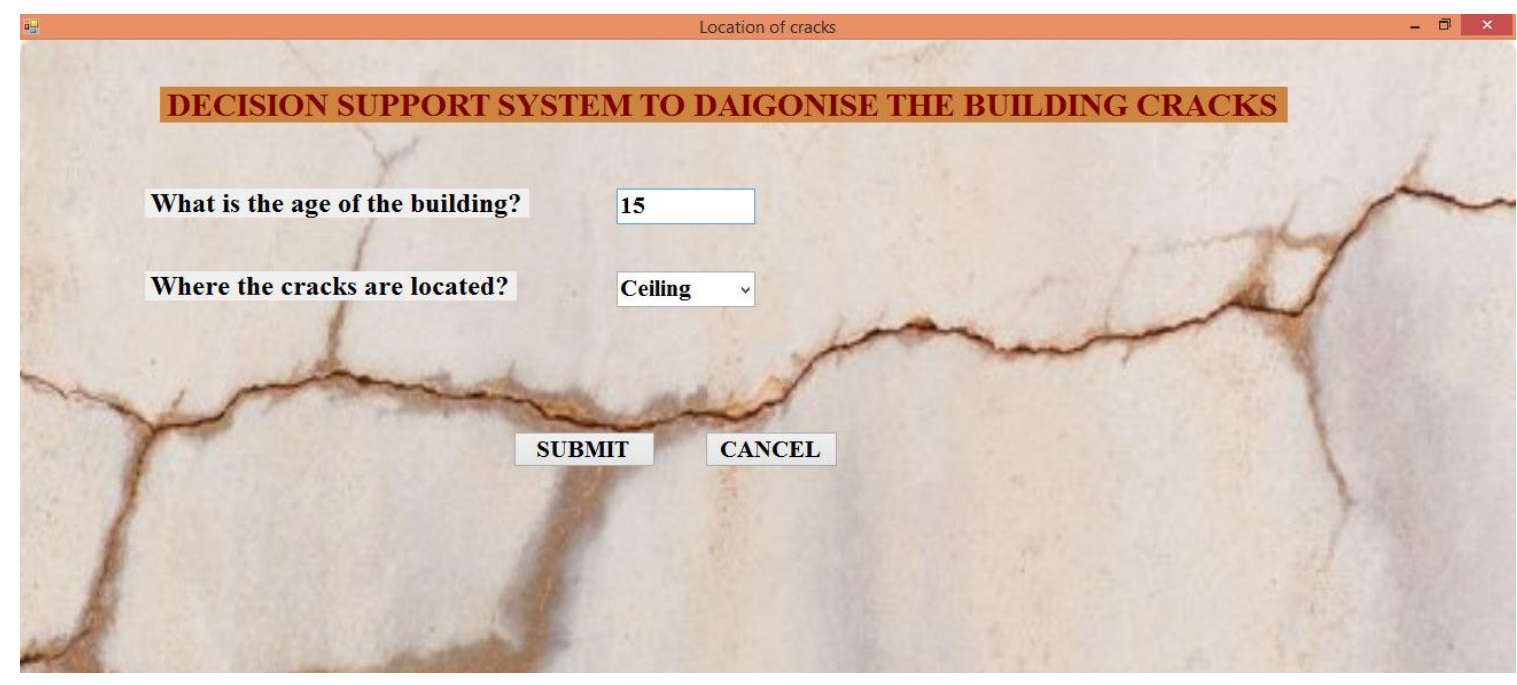

Figure 2: Typical query session 




Figure 3: Query related to ceiling (Video assisted)

\begin{tabular}{|c|c|}
\hline$\square$ & CeilingReports \\
\hline 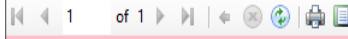 & $100 \% \quad$ Find $/$ Nert \\
\hline & ial Report For Building Cracks \\
\hline Causes for the crack & $\begin{array}{l}\text { By the queries and responses, the reasons for the building cracks } \\
\text { were predicted. The predicted location of the crack is on the } \\
\text { middle of the ceiling. Main causes for this crack is due to the } \\
\text { heavy moisture present on the top, improper roof drainage or a } \\
\text { plumbing leak from the floor above and temperature fluctuations } \\
\text { could also lead to the cracking. Although cracks along the edges of } \\
\text { a ceiling are a normal part of home's settling or movement and } \\
\text { weight on the ceiling due to multistorey building. }\end{array}$ \\
\hline Remedial measures for the crack & $\begin{array}{l}\text { It is suggested that the below steps need to be followed to } \\
\text { overcome the above predicted crack on the ceiling of the building. } \\
\text { "remove old drywall patches and tape. *attach screws to attic } \\
\text { blocks. "widen the ceiling cracks. *apply drywall tape and mud. } \\
\text { "smooth the surface. *sand and paint. }\end{array}$ \\
\hline
\end{tabular}

Figure 4: Suggested remedial measures 


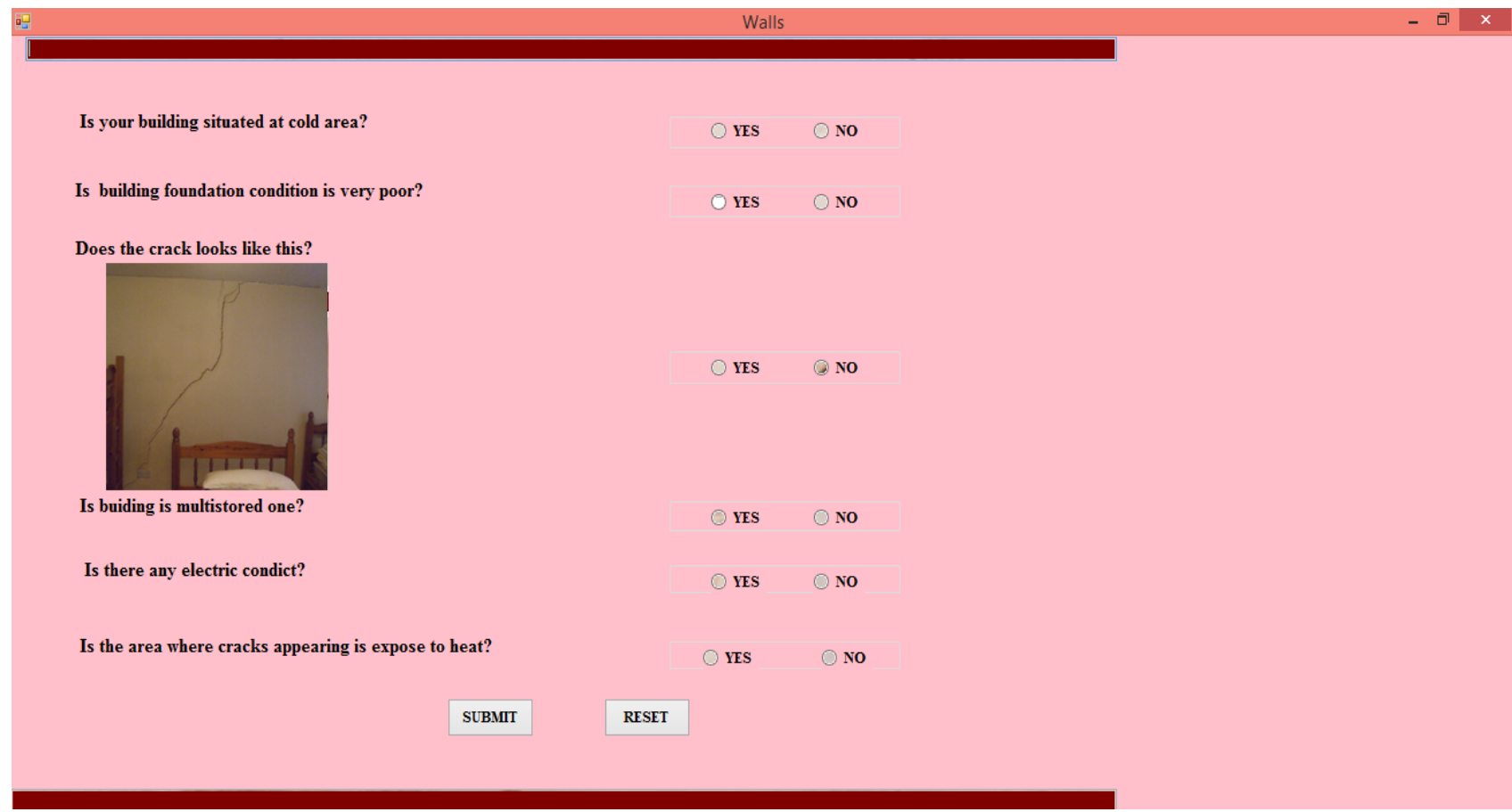

Figure 5: Query related to cracks in walls



Figure 6: Query related to cracks in columns.

\section{CONCLUSION}

This paper presented the description of the development of a decision support system for diagnosing, detecting and suggesting remedial measures for building cracks. The system so developed was tested for its suitability and correctness before civil engineers and it is evaluated to be satisfactory. However there is a scope for additional details pertaining to recent developments in building technology.

\section{ACKNOWLEDGMENTS}

The authors wish to place on records the Faculty members of Department of Civil Engineering, Siddaganga Institute of
Technology for their invaluable help and suggestions while developing the system.

\section{REFERENCES}

[1] Rodolfo Baggio, Leonardo Caporaresllo, Decision Support Systems in a Tourism Destination: Literature Survey and Model Building, proceedings of 2nd conference of the Italian chapter of Association for Information Systems, Verona, Italy 1-2 December 2005, $1-15$.

[2] M. Senthil Velmurugan, Kogilah Narayanasamy, Application of Decision Support System in E-commerce, 
proceedings of Communications of the IBIMA Volume 5, 2008, 156-169.

[3] M.A.Jayaram, Shilpa.B, Intelligent System for Diagnosing Learning Disorders in Children, proceedings of World Congress on Engineering and Computer Science 2010, San Francisco, USA 20-22 October, 2010, 70-75.

[4] Mariann Fossun, 2014, A Computerized Decision Support System in Nursing Homes, thesis submitted to OREBRO university, 1-77.

[5] Nomusa Dlodli, Lawrance Hunter, Cyprian Cele, Anton F. Botha, Roger Metelerkamp, proceedings of A Decision Support System For Wool Classification, AUTEX Research Journal, Vol.9, No2, 2009, 42-46.

[6] Regin Joy Conejar, Haeng-Kon Kim, A Medical Decision Support System(DSS) for Ubiquitous Healthcare Diagnosis System, proceedings of International Journal of Software Engineering and Its Applications, Vol.8, No. 10 (2014), 237-244.

[7] Noor MaizuraMohamad Noor, Ahmad Faiz Ghazali, Rosmatayi Mohemad, MD Yazid Mohd Saman, 2015,Decision Support System Is A Tool for Making Better Decisions In The Organization, proceedings of Journal of Theoretical and Applied Information Technology, September,Vol.79.No.2, 272-278.

[8] Navneet Walia, Harsukpreet Singh, Sharad Kumar Tiwari and Anurag Sharma, proceedings of International Journal of Soft Computing (IJSC), Vol.6, No. 3, 2015, $1-14$.

[9] Ermatita, Sri Hartati, Retantyo Wardoyo, Agus Harjoko, Electre Methods In Solving Group Decision Support System Bioinformatics On Gene Mutation Detection Simulation,2011, proceedings of International Journal of Computer Science and Information Technology (IJCSIT), Vol 3, No 1, February, 40-52.

[10] Raul Valverde, A Risk Management Decision Support System for the Real Estate Industry, 2011, proceedings of International Journal Of Information and Communication Technology Rrsearch, Vol 1, No.3, July, 139-147.
[11] K.P.Tripaty, Decision Support System is a Tool for Making Better Decisions in the Organization, Indian Journal of Computer Science and Engineering, Vol.2, No. 1, 2013, 112-117

[12] Grishma Thagunna, Building cracks - causes and remedies, proceedings of International Journal of Advanced Structures and Geotechnical Engineering , Vol.4, No.1, 2015, 16-20.

[13] Recommendations for the prevention of ceiling cracking, 2013, A report, Gypsum association, 1-4.

[14] Benjamin Roussey, Why Is My Ceiling Cracking? : Available at https://www.redbeacon.com/hg/why-myceiling-cracking/

[15] Saurabh, Types of Wall cracks, Available at: http://www.fropky.com/types-wall-cracks-vt34382.html

[16] Mohamed Abdalla Almherigh, Common Causes of Cracking in Masonry Walls Diagnosis and Remedey, International Journal of Sciences: Basic and Applied Research (IJSBAR), 2014, Vol 14, No 1, 25-33.

[17] Pooja Nama,Ankush Jain, Rajat Srivastava and Yash Bhatia, Study on Causes of Cracks \& its Preventive Measures in Concrete Structures, 2015, proceedings of International Journal of Engineering Research and Applications, Vol. 5, Issue 5, (Part 2) May , 119-123.

[18] Types of cracks in concrete columns, available at: http://theconstructor.org/concrete/types-of-cracks-inconcrete-columns/5952/

[19] Types of cracks in concrete beams, available at: http://theconstructor.org/concrete/types-of-cracks-inconcrete-beams/5948/

[20] Grigory Yakovlev, Nikolai Khokhriakov, Crack Formation in Vacuum Concrete, Journal of Civil Engineering and Management, 2002, Vol 8, No 2, 117 120.

[21] How to evaluate cracks in poured concrete slabs \& floors, available at: http://inspectapedia.com/structure/Concrete_Floor_Crack s.php 